\title{
SAFETY AND EFFICACY OF A LOW DOSE CORTICOSTEROID REGIMEN FOR THE INDUCTION TREATMENT OF LUPUS NEPHRITIS - CYCLONES TRIAL: CYCLOPHOSPHAMIDE LOW DOSE AND NO EXTRASTEROID
}

Michelle Lopes ${ }^{1}$, Sandra Gofinet Pasoto ${ }^{1}$, Emily Figueiredo Neves Yuki ${ }^{1}$, Lorena Elizabeth Betancourt Villamarín ${ }^{1}$, Francisco Fellipe Claudino Formiga ${ }^{1, \star}$, Débora Cordeiro do Rosário ${ }^{1}$, Leticia Maria Kolachinski Raposo Brandão ${ }^{1}$, Carolina Torres Ribeiro ${ }^{1}$, Tatiana do Nascimento Pedrosa ${ }^{1}$, Alex Cardoso Lopes ${ }^{1}$, Eduardo Ferreira Borba ${ }^{1}$, Luciana Parente Costa Seguro ${ }^{1}$, Nádia Emi Aikawa $^{1}$, Eloisa Silva Dutra de Oliveira Bonfá ${ }^{1}$

1.Universidade de São Paulo, São Paulo (SP), Brazil.

*Corresponding author: fellipeclaudino@hotmail.com

\section{BACKGROUND}

In the last few years, there is a large effort to minimize the use of glucocorticoids (GC) in the treatment of systemic lupus erythematosus (SLE). Although CGs greatly increased the survival of SLE patients in the past, its excessive use is responsible for a considerable amount of irreversible damage. The aim of this study was to evaluate the efficacy and safety of a lupus nephritis (LN) induction treatment scheme with lower than standard doses of GC.

\section{METHODS}

CYCLONES (CYClophosphamide LOW dose and No Extra Steroid) trial is a randomized controlled open-label noninferiority clinical trial with blinded endpoint adjudication. The CYCLONES group received six doses of methylprednisolone $(500 \mathrm{mg}$ on D0/D15 + $250 \mathrm{mg}$ on D30/D45 + $125 \mathrm{mg}$ on D60/D75) and low dose oral GC. Prednisone was immediately adjusted to $20 \mathrm{mg} /$ day and tapered down ( $5 \mathrm{mg} / \mathrm{month}$ ) until complete withdrawal. CYCLONES was compared with the EUROLUPUS group that received three consecutive doses of methylprednisolone $(750 \mathrm{mg}$ on D0, D1, D2) + prednisone $0.5 \mathrm{mg} / \mathrm{kg} /$ day with a gradual reduction of $5 \mathrm{mg} / \mathrm{month}$. Both groups received cyclophosphamide ( 6 doses of $500 \mathrm{mg}$ biweekly) followed by azathioprine or mycophenolate mofetil, until the completion of 6 months. The primary outcome was a partial renal at week 24 defined as urinary protein/creatinine ratio $(P / C)<3 \mathrm{~g} / \mathrm{g}$ with decrease of at least $50 \%$ from baseline + increase of creatinine ( $\mathrm{mg} / \mathrm{dL}$ ) not higher than $15 \%$ from baseline.

\section{RESULTS}

A total of 45 patients completed the 6 months of treatment (22 in CYCLONES and 23 in EUROLUPUS). The primary outcome was achieved in 11 (50\%) patients in the CYCLONES compared to 19 (83\%) patients in EUROLUPUS. The noninferiority test failed, the Cox regression hazard ratio for not achieving the primary outcome in the CYCLONES was HR $=2.69(95 \% \mathrm{Cl}=1.28-5.68, p=0.009)$. Creatinine change from baseline was comparable between groups ( $-0.07 \pm 0.31 \mathrm{vs} .-0.13 \pm 0.39, p=0.54)$ as well as creatinine at 6 months ( $0.79 \pm 0.20$ vs. $0.89 \pm 0.37, p=0.27)$. Cumulative prednisone dose was different between both groups at 6 months (2025 $\pm 900 \mathrm{mg}$ vs. $3704 \pm 1067 \mathrm{mg}, \mathrm{p}<0.0001)$. There were no deaths and only one serious adverse event in EUROLUPUS group.

\section{CONCLUSION}

CYCLONES was inferior to EUROLUPUS in achieving the primary outcome of proteinuria at 24 weeks, although within the range reported for large nephritis induction trials. Sustained and comparable levels of creatinine were observed among groups. Alternative schemes are needed to evaluate the best approaches to reduce GC induced damage in LN treatment. This trial was registered at www.clinicaltrials.gov as \#NCT 03492255.

\section{KEYWORDS}

Lupus nephritis, Steroids, Cyclophosphamide. 